\title{
Leveraging vascular quality initiative data to improve hospital length of stay for patients undergoing endovascular aneurysm repair
}

\author{
Naomi Eisenberg, PT, MEd \\ Graham Roche-Nagle, MD, MBA \\ Thomas F. Lindsay, MDCM, MSc \\ George Oreopoulos, MD, MSc
}

Presented at the annual meeting of the Canadian Society for Vascular Surgery, Sept. 16-17, 2016, Halifax, NS

Accepted July 11, 2019

\author{
Correspondence to: \\ G. Oreopoulos \\ Vascular Surgery Residency Program \\ University Health Network \\ 6E 216, 200 Elizabeth St \\ Toronto ON M5C 2G4 \\ george.oreopoulos@uhn.ca
}

DOI: $10.1503 /$ cjs.003219

\begin{abstract}
Background: The Society for Vascular Surgery Vascular Quality Initiative (SVS-SVQI) is a database that provides insight into standards of care and highlights opportunities for quality improvement by benchmarking institutional data against local, regional and national trends. Endovascular aneurysm repair (EVAR) is a frequently performed vascular operation. Postoperative length of stay in hospital (LOS) varies among institutions. We reviewed the morbidity and mortality of patients who underwent EVAR at our institution and the financial impact of increased LOS for these patients. In addition, we sought to identify modifiable factors associated with prolonged LOS.
\end{abstract}

Methods: We identified all patients who underwent elective EVAR between Jan. 1, 2011, and Dec. 31, 2014. Preoperative patient characteristics, intraoperative details, postoperative factors, long-term (1 yr) outcomes and cost data were reviewed. Univariate analysis was used to determine statistical differences between patients with LOS less than or equal to 2 days and greater than 2 days. Interventions were implemented to modify factors identified as having a negative impact on EVAR LOS.

Results: Identified factors that negatively affected EVAR LOS included social, neurologic, cardiovascular, urologic and renal issues. Following targeted interventions, LOS after EVAR decreased from an average of 3.8 to 3.0 days $(p<0.05)$. Logistic regression $(n=124)$ identified cardiovascular issues as the most significant predictor of LOS greater than 2 days ( $p=0.001$, odds ratio $14.24,95 \%$ confidence interval $2.8-71.4)$. Reduction in LOS was associated with the additional benefit of $6.6 \%$ adjusted cost savings.

Conclusion: By leveraging SVS-VQI data, we were able to reduce EVAR LOS by identifying modifiable factors and instituting focused interventions. The reduction in LOS was associated with cost savings to the hospital.

Contexte : L'Initiative pour la qualité de la chirurgie vasculaire de la Société canadienne de chirurgie vasculaire (IQCV-SCCV) est une base de données qui donne un aperçu des normes thérapeutiques et souligne les possibilités d'améliorations de la qualité en faisant la comparaison entre les tendances institutionnelles et les tendances locales, régionales et nationales. La réparation endovasculaire d'anévrisme (REVA) est une intervention fréquente. La durée du séjour hospitalier postopératoire varie d'un établissement à l'autre. Nous avons examiné la morbidité et la mortalité chez les patients ayant subi une REVA dans notre établissement et mesuré l'impact économique d'un séjour hospitalier prolongé chez ces patients. De plus, nous avons tenté de dégager les facteurs modifiables associés à un séjour prolongé.

Méthodes : Nous avons recensé tous les patients ayant subi une REVA entre le $1^{\text {er }}$ janvier 2011 et le 31 décembre 2014. Nous avons pris en compte les caractéristiques préopératoires des patients, les détails peropératoires, les facteurs postopératoires, les résultats à long terme $(1 \mathrm{an})$ et les coûts. Une analyse univariée a servi à déterminer les différences statistiques entre les patients ayant séjourné à l'hôpital 2 jours ou moins et plus de 2 jours. Des interventions ont été appliquées pour modifier les facteurs reconnus pour leur impact négatif sur le séjour hospitalier après une REVA.

Résultats : Les facteurs identifiés pour leur effet négatif sur le séjour hospitalier après une REVA étaient entre autres problèmes sociaux, neurologiques, cardiovasculaires, urologiques et rénaux. Après l'application d'interventions ciblées, la durée du séjour hospitalier post-REVA a diminué d'une moyenne de 3,8 à 3,0 jours $(p<0,05)$. La régression logistique $(n=124)$ a permis d'identifier les problèmes cardiovasculaires comme principaux prédicteurs d'un séjour hospitalier de plus de 2 jours $(p=0,001$, rapport des cotes 14,24 , intervalle de confiance de $95 \%$ 2,8-71,4). L'abrègement du séjour hospitalier a été associé à un avantage additionnel de 6,6\% en économies de coûts ajustées.

Conclusion : Après analyse des données de l'IQCV-SCCV, nous avons réussi à abréger la durée des séjours hospitaliers pour REVA en identifiant les facteurs modifiables et en appliquant des interventions ciblées. L'abrègement des séjours hospitaliers a été associé à des économies pour l'hôpital. 
$\mathrm{H}$ ealth care is the single largest budget item for every province and territory in Canada. In 2019, total health expenditure in Canada is expected to reach $\$ 264$ billion, or $\$ 7068$ per person. It is anticipated that, overall, health spending will represent $11.5 \%$ of Canada's gross domestic product (GDP). ${ }^{1}$ It is therefore imperative to focus on providing high-quality, cost-effective care. Reducing hospital length of stay (LOS) after routine procedures has been cited as a quality metric to reduce costs and hospital-acquired morbidity.

The Society for Vascular Surgery Vascular Quality Initiative (SVS-VQI) is a Web-based database that holds data for more than 400 medical centres in the United States and Canada. ${ }^{2}$ Its purpose is to improve the quality of vascular care by encouraging physicians and facilities to share data in a collaborative manner. Individual institutions can review their data and compare them with risk-adjusted outcomes. As of January 2019, 525 centres were participating, encompassing 46 US states, 4 Canadian provinces and, most recently, Singapore. The SVS-VQI is governed by the Society for Vascular Surgery's Patient Safety Organization, which provides oversight for data monitoring and quality reports. The SVS-VQI comprises procedurespecific modules to which individual centres can subscribe. Whereas other databases (namely, the American College of Surgeons' National Surgical Quality Improvement Program [NSQIP]) ${ }^{3}$ collect samplings of data, the SVS-VQI prospectively collects all eligible and sequential case information as well as 30-day and 1-year follow-up data for all procedures. On a regular basis, the SVS-VQI sends its members quality reports to allow those centres to identify and address quality concerns.

Our institution was the first in Canada to join SVSVQI. Early in our experience with SVS-VQI, we received a report indicating that our centre's observed LOS for endovascular aneurysm repair (EVAR) was higher than our risk-adjusted expected value (Fig. 1). This report was taken as an opportunity to improve the LOS for patients who undergo EVAR at our institution.

The purpose of our study was to address 2 questions. Using the quality cycle (plan-do-study-act; PDSA), ${ }^{4}$ could we intervene to decrease our LOS following elective EVAR? If successful, what financial savings would result?

\section{Methods}

The analytics engine in SVS-VQI allows institutions to generate custom reports either for a single procedure or across procedures, depending on the variables selected. Filters can be applied to narrow the population of interest, and reports are produced that can incorporate benchmarking for the centre, the region and/or the rest of the institutions participating in SVS-VQI. The early SVS-VQI analytics engine allowed for the production of a risk-adjusted report predicting the expected LOS. The expected LOS of our cohort calculated by SVS-VQI was less than 2 days. We therefore defined a prolonged LOS after elective EVAR as being greater than 2 postoperative days in hospital.

We interrogated SVS-VQI for 2 discrete time periods to review our LOS for all patients undergoing elective infrarenal EVAR. Our initial cohort (Jan. 1, 2011, to Dec. 31, 2012) was defined as our preintervention study cohort. All charts were manually reviewed for demographic data, preoperative comorbidities, operative complications and any postoperative complications, some of which are not currently captured by SVS-VQI. Examples include neurologic issues (e.g., delirium) and urologic issues (eg., urinary retention). Patients undergoing advanced endovascular grafting

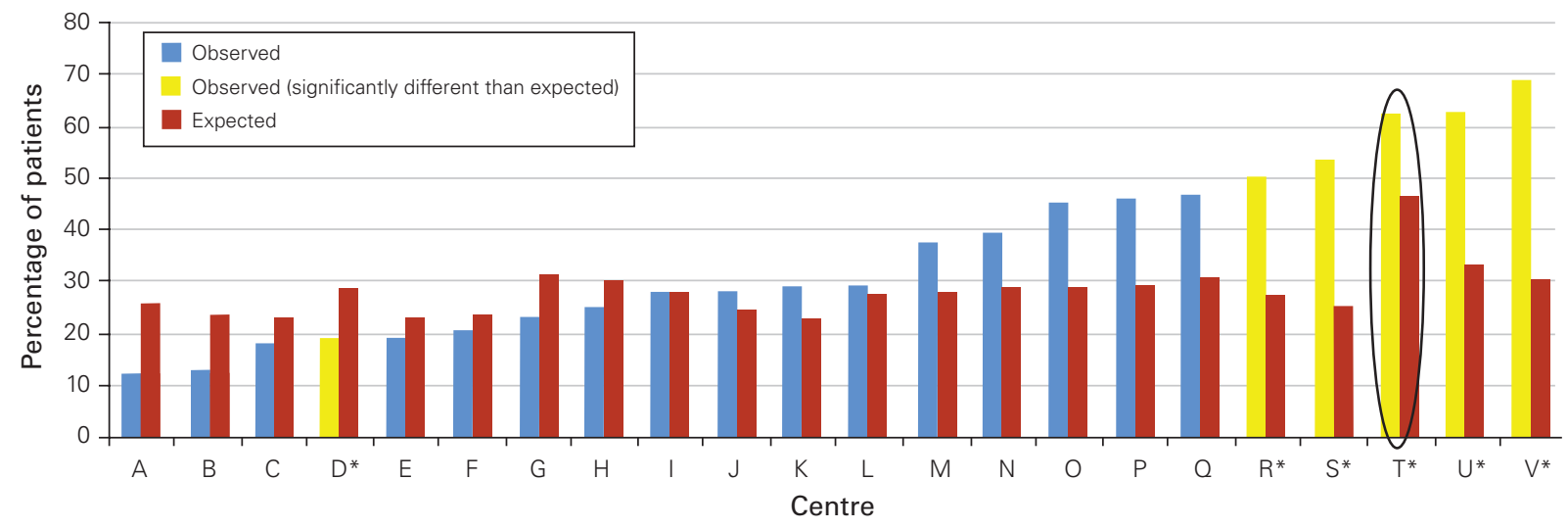

Fig. 1. Observed and expected percentage of patients with hospital length of stay (LOS) greater than 2 days after nonruptured endovascular aneurysm repair (2003-2011) for hospitals with 18 or more procedures that participate in the Society for Vascular Surgery Vascular Quality Initiative (SVS-VQI). In-hospital deaths were excluded. Data for our centre are circled. ${ }^{*}$ Centre at which the observed percentage of patients with LOS greater than 2 days was significantly lower or higher than expected. Data used with permission of SVS-VQI. 
(branched and fenestrated devices) or urgent/emergency repair were excluded. Preoperative comorbidities, social issues, intraoperative variables and postoperative complications were documented. We then reviewed the subset of patients undergoing elective EVAR who had stayed longer than our SVS-VQI LOS quality benchmark of 2 days, to determine responsible factors. Data for a subset of patients who stayed 6 or more days postoperatively were also analyzed. Our local vascular surgery business unit was used as a multidisciplinary forum to plan and implement strategies to mitigate the effects of variables associated with a prolonged LOS. This is a multidisciplinary group of clinical and administrative staff who meet regularly to address the operational issues of the service.

Our targeted interventions focused on preoperative counselling of the patient, family, nurses and residents to manage their expectations regarding the patient's postoperative LOS: we informed them that the goal was discharge within 2 days. We eliminated the immediate preoperative insertion of urinary catheters, minimized the use of opioids for postoperative pain relief with prescriptions for standing doses of acetaminophen, and encouraged early mobilization (through patient and caregiver counselling and modified orders in the step-down unit). To mitigate against accessrelated wound complications incurred with open surgical cut-down of the femoral arteries for stent graft insertion, we shifted to a totally percutaneous access approach using an ultrasound-guided puncture and "preclose" technique. For patients with previous open surgical access or severely calcified femoral arteries on preoperative computed tomography angiography, access was by open surgical technique.

Following the implementation of our targeted interventions, we repeated our analysis with a second cohort of patients (Jan. 1, 2013, to Dec. 31, 2014), defined as our postintervention cohort, to determine the impact of the interventions on EVAR LOS. An additional review was conducted to identify any unscheduled hospital readmissions or emergency department (ED) visits for both cohorts. Hospital cost data were obtained through the case costing centre at our institution.

Data were analyzed using SPSS software with the aid of a statistical consultant. Local research ethics board approval was received for the study. Overall differences in LOS were analyzed with the Mann-Whitney $U$ test, and differences in comorbidities between cohorts were analyzed with $\chi^{2}$ and Fisher exact tests. Univariate predictors of LOS greater than 2 days were analyzed individually with the Fisher exact test using Monte Carlo sampling. To match previous analyses, predictors reaching significance at the 0.02 level were considered for further analysis. These predictors were entered into a final logistic regression predicting LOS greater than 2 days, which is the SVS-VQI benchmark. Issues on postoperative day 1 were used as predictors and included wound, cardiovascular, respiratory, renal, neurologic and urologic issues.

\section{Results}

We identified 237 patients who underwent elective EVAR during the entire study period, 113 in the preintervention cohort and 124 in the postintervention cohort. Table 1 summarizes the preoperative characteristics of patients undergoing EVAR in both cohorts. The cohorts were very similar except in terms of the percentage of patients classified as American Society of Anesthesiologists (ASA) class 4 and the percentage of patients with a cardiac history (identified by SVS-VQI as having the presence of, or a history of, coronary artery disease, congestive heart failure, coronary artery bypass grafting or percutaneous coronary intervention). The preintervention cohort had an average LOS of $3.8 \pm 3.61$ days, with $59(52.2 \%)$ having an LOS greater than 2 days. Table 2 lists postoperative factors that contributed to an extended LOS. Cardiovascular and renal injury, as indicated by postoperative myocardial infarction (indicated by either troponin increase or electrocardiographic changes), new dysrhythmias (treated by medications or intervention) and changes in renal function (creatinine increase $>44.8 \mathrm{mmol}$ ), were major predictors of increased LOS in patients.

Following the introduction of the targeted interventions, we examined our data postintervention (Jan. 1, 2013, to Dec. 31, 2014). Figure 2 shows the change in mean LOS by frequency; LOS decreased from 3.83 (standard deviation [SD] 3.558) days to 3.04 (SD 4.891) days $(p<0.05)$. Fiftyfour patients in the preintervention cohort $(47.8 \%)$ had an LOS of 2 days or less. There was a significant difference in

Table 1. Preoperative characteristics of study patients

\begin{tabular}{|c|c|c|c|}
\hline \multirow[b]{3}{*}{ Characteristic } & \multicolumn{2}{|c|}{ Percentage of patients; cohort } & \multirow[b]{3}{*}{$p$ value } \\
\hline & $\begin{array}{l}\text { Preintervention } \\
\text { cohort } \\
\text { (2011-2012) }\end{array}$ & $\begin{array}{l}\text { Postintervention } \\
\text { cohort } \\
\text { (2013-2014) }\end{array}$ & \\
\hline & $n=113^{*}$ & $n=124^{*}$ & \\
\hline Elderly (> 80 yr), \% & 27.4 & 39.5 & NS \\
\hline Living alone, \% & 81.7 & 80.7 & NS \\
\hline Smoker, \% & 22.3 & 16.9 & NS \\
\hline \multicolumn{4}{|l|}{ Sex, \% } \\
\hline Male & 86.7 & 84.7 & NS \\
\hline Female & 13.3 & 15.3 & \\
\hline Obese, \% & 39.3 & 26.8 & NS \\
\hline GTA, \% & 81.9 & 83.9 & NS \\
\hline $\begin{array}{l}\text { Postoperative CTA } \\
\text { done, \% }\end{array}$ & 23.4 & 18.5 & NS \\
\hline $\mathrm{Ml}, \%$ & 45.1 & 31.5 & 0.033 \\
\hline $\mathrm{PCl}, \%$ & 22.5 & 12.1 & 0.038 \\
\hline CRF，\% & 13.3 & 16.13 & \\
\hline ASA class $4, \%$ & $\begin{array}{c}63.4 \\
(n=31)\end{array}$ & $\begin{array}{c}90.2 \\
(n=111)\end{array}$ & $<0.001$ \\
\hline \multicolumn{4}{|c|}{$\begin{array}{l}\mathrm{ASA}=\text { American Society of Anesthesiologists; } \mathrm{CRF}=\text { chronic renal failure; } \mathrm{CTA}= \\
\text { computerized tomographic angiography; } \mathrm{GTA}=\text { greater Toronto area; } \mathrm{MI}=\text { myocardial } \\
\text { infarction; } \mathrm{NS}=\text { nonsignificant; } \mathrm{PCl}=\text { percutaneous coronary intervention. } \\
\text { *Unless indicated otherwise. }\end{array}$} \\
\hline
\end{tabular}




\begin{tabular}{|c|c|c|}
\hline \multirow[b]{3}{*}{ Factor } & \multicolumn{2}{|c|}{ Percentage of patients; cohort } \\
\hline & $\begin{array}{l}\text { Preintevention } \\
\text { cohort (2011-2012) }\end{array}$ & $\begin{array}{c}\text { Postintevention } \\
\text { cohort (2013-2014) }\end{array}$ \\
\hline & $n=113$ & $n=124$ \\
\hline $\begin{array}{l}\text { Intraoperative } \\
\text { complications* }\end{array}$ & 5.3 & 10.0 \\
\hline $\begin{array}{l}\text { Discharge issues predicted } \\
\text { on preadmission }\end{array}$ & 14.2 & 14.4 \\
\hline \multicolumn{3}{|l|}{ Postoperative day 1} \\
\hline Wound factorst & 6.5 & 3.2 \\
\hline Cardiovascular factors $\ddagger$ & 11.1 & 8.1 \\
\hline Respiratory factors§ & 4.7 & 1.6 \\
\hline Renal factors & 2.8 & 6.5 \\
\hline Neurologic factors** & 0.9 & 1.6 \\
\hline Urologic factorst† & 4.4 & 5.6 \\
\hline \multicolumn{3}{|l|}{ Postoperative day 2} \\
\hline Wound factors ${ }^{\dagger}$ & 13.0 & 5.9 \\
\hline Cardiovascular factors $\ddagger$ & 20.2 & 26 \\
\hline Respiratory factors§ & 5.1 & 2 \\
\hline Renal factors & 5.1 & 13.7 \\
\hline Urologic factorst† & 11.1 & 13 \\
\hline \multicolumn{3}{|c|}{$\begin{array}{l}\text { *Endoleak, excessive blood loss, failure of percutaneous access. } \\
\text { tSwelling, ecchymosis, oozing, need for reinforcement, hematoma, etc. } \\
\text { \#Increased troponin, dysrhythmia, hypertension, hypotension. } \\
\text { §Need for supplemental } \mathrm{O}_{2} \text {, secretions. } \\
\text { १Elevated creatinine. } \\
\text { ** Confusion. } \\
\text { † UUrinary retention. }\end{array}$} \\
\hline
\end{tabular}

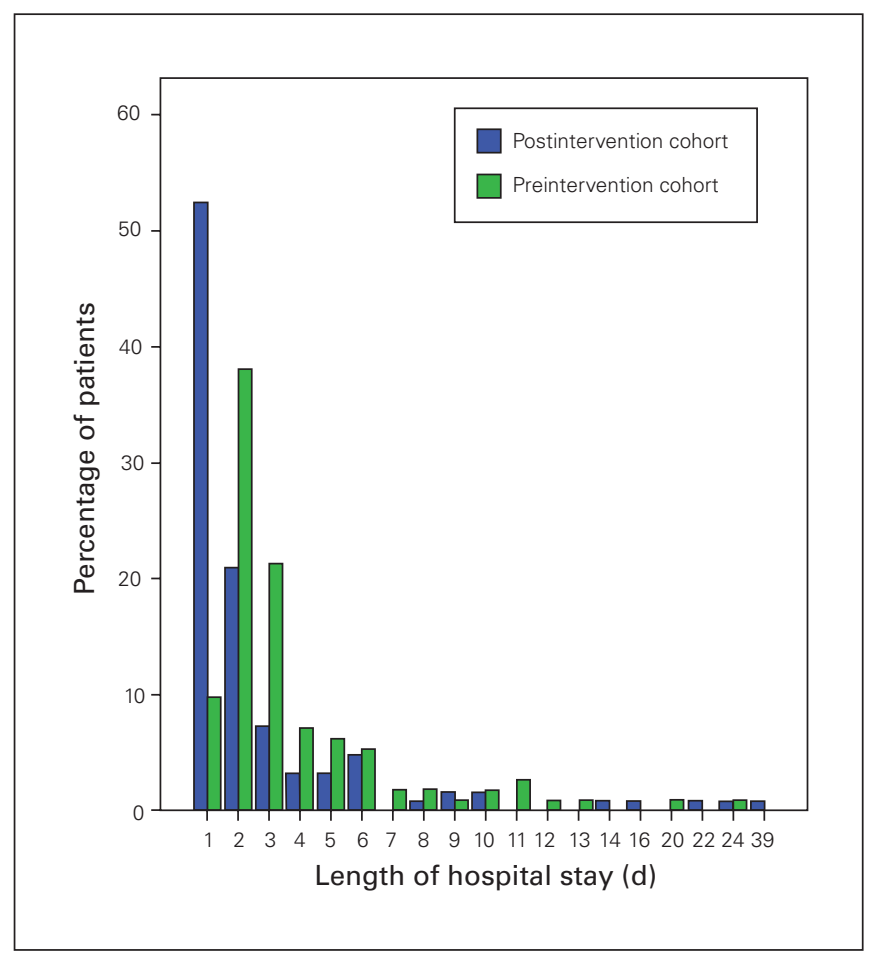

Fig. 2. Hospital length of stay for the preintervention (2011-2012) and postintervention (2013-2014) cohorts.
LOS between the 2 cohorts $\left(26.6 \%\right.$ v. $52.2 \%, \chi^{2}=16.31$, $p<0.001$ ) (Fig. 2). There were no deaths in either the preintervention or the postintervention cohort at 1 year.

Univariate predictors of LOS less than or equal to 2 days were examined for each patient in the postintervention cohort individually with Fisher exact tests $(n=124)$. Bootstrapping was used because of the low numbers of events in some categories. Even so, some of the results should be interpreted with caution. That said, these results were the most complete that could be generated.

The Monte Carlo resampling method of bootstrapping (1000 samples) and exact 2-sided significance values (v. asymptotic) were used for all univariate comparisons to account for unbalanced data. To coincide with the model built using the database for the preintervention cohort, only variables where the $p$ values were less than 0.02 were considered for the final model. A linear-by-linear $\chi^{2}$ analysis (i.e., Mantel-Haenszel linear-by-linear association) was also assessed as a check, and the results were the same. The only variable reaching significance was cardiovascular issues on postoperative day 1 . This variable was then added to a logisitic regression model predicting LOS greater than 2 days. The results can be seen in Table 3. Although the odds ratio is 14.24 , the wide confidence interval indicates that this result should be interpreted with caution.

\section{Financial analysis}

We were able to save a total of 34 hospital days for the postintervention cohort, and unadjusted average costs decreased from $\$ 27191$ to $\$ 26275$, a difference of $\$ 916$. When we adjusted for inflation using the Bank of Canada's inflation calculator using 2001 dollars (www. bankofcanada.ca/rates/related/inflation-calculator/), costs decreased from $\$ 22021$ to $\$ 20568$, a difference of $\$ 1453$ per case, which is a $6.6 \%$ decrease.

We reviewed readmission and ED visits for both cohorts. In the first cohort, there were 5 readmissions (4.4\%) and $6 \mathrm{ED}$ visits $(5.3 \%)$ and in the second cohort there were 4 readmissions (3.2\%) and $8 \mathrm{ED}$ visits (6.5\%). Neither of these differences were found to be statistically significant by $\chi^{2}$ analysis $(p>0.05)$

\section{Discussion}

Using SVS-VQI, we identified an opportunity to improve the quality of care for our patients with regard

Table 3. Logistic regression results predicting hospital length of stay greater than 2 days

\begin{tabular}{lccc} 
Variable & $\beta(\mathrm{SE})$ & OR $(95 \% \mathrm{Cl})$ & $p$ value \\
\hline $\begin{array}{l}\text { Cardiovascular factors } \\
\text { on postoperative day } 1\end{array}$ & $2.65(6.5)$ & $14.24(2.8-71.4)$ & 0.001 \\
\hline $\mathrm{Cl}=$ confidence interval; $\mathrm{OR}=$ odds ratio; SE = standard error. & \\
\hline
\end{tabular}


to LOS. We reviewed the causes of our extended LOS and instituted a number of simple targeted interventions to address the problem. Multidisciplinary engagement, initially at the level of our vascular business unit, allowed staff to reach consensus on how to address the issue that patients who underwent elective EVAR at our centre had a higher than expected LOS. A number of interventions were introduced following discussion with our anesthesia and nursing colleagues, including the use of standing acetaminophen for pain in the postoperative period, use of percutaneous access where appropriate, elimination of urinary catheter insertion unless there was postoperative retention and early mobilization in the immediate postoperative period $(4 \mathrm{~h})$. In the vascular clinic, we began to manage the patients' and families' expectations assertively, preparing them for a discharge on the first postoperative day unless there were unexpected medical concerns. In addition, we provided more focused education on the procedure and postoperative complications. Our results indicate that our interventions have been successful. In addition to decreasing our expenditures, we noted that hospital readmissions decreased by approximately $33 \%$.

There is sparse literature concerning the drivers of LOS for EVAR. King and colleagues ${ }^{6}$ used data from NSQIP to identify that chronic renal insufficiency, dependent functional status, recent weight loss, congestive heart failure, high ASA class, female sex and non-white race were predictors of extended LOS. Patel and colleagues ${ }^{7}$ performed a univariate analysis of their local institution's data and identified increased age, female sex, smoking, coronary artery disease, chronic obstructive pulmonary disease, prior abdominal aortic aneurysm repair, elevated creatinine and larger abdominal aortic aneurysm size as factors. Our demographic analysis found only ASA class to be significantly different between the cohorts.

With respect to the financial impact of increased LOS, there was, again, very little literature that addressed our challenge. Two studies, 1 American $^{8}$ and 1 British, ${ }^{9}$ found that some of the factors that drove increased LOS were modifiable. We found no Canadian data. Mehaffey and colleagues $^{8}$ identified modifiable risk factors at different points on the patient's continuum of care; in other words, different pre-, peri- and postoperative factors played a role. They identified preoperative factors, including ASA class and congestive heart failure, as the most relevant. Perioperative factors included procedure time, volumes of contrast and crystalloid, and hypogastric artery coiling. Finally, they found that concomitant procedures, admission to the intensive care unit and postoperative renal and cardiac issues all contributed to increased LOS. Although we have reduced our use of iodinated contrast, this was not significant in our logistic regression analysis. Mehaffey and colleagues ${ }^{8}$ also found that extended LOS led to increased 30-day and 1-year morbidity and mortality and that although hospital charges were higher, physician charges remained the same. With the introduction of percutaneous access for EVAR (pEVAR), our operative time has been reduced, but we continue to use general anesthesia over local anesthesia in our training environment as a teaching hospital. One of the limitations of our present study is that it was a single-centre study, and therefore generalizability would be limited. Further, the study by Mehaffey and colleagues ${ }^{8}$ took place outside of Canada, so costs between the 2 systems cannot be compared easily. In another British study, Al-Zuhir and colleagues ${ }^{9}$ identified that urinary retention contributed to extended LOS, similar to our results, and found that transportation/social issues and unexpected technical difficulty drove costs. By focusing on these factors, they were able to decrease their costs by $£ 2000$.

An important point to be addressed is the introduction of percutaneous access for EVAR and same-day discharge. Our centre has been increasing its use of percutaneous EVAR over the last several years and this is currently our preferred method of femoral access. Funding models in Ontario require an overnight stay for hospital reimbursement for aneurysm repair; should this model change, then this would be an important area for ongoing study, and we would anticipate both further savings and decreased LOS. Recently, Hanley and colleagues ${ }^{10}$ described their Canadian experience and reported that approximately $40 \%$ of their population would meet their criteria for same-day discharge. Careful selection of their patients (patients undergoing elective surgery who had low surgical risk and who had a caregiver available for the first $24 \mathrm{~h}$ ) was required. Outpatient EVAR was successful for $79 \%$ of their cohort, but they also found that a higher, although not statistically significant, number of patients returned to the ED after the same-day procedure.

The clinical relevance of shortening LOS by 0.76 days is important to note. We believe that we can safely extrapolate this to a night in hospital. Although we have noted no change in readmission rates in our centre, this was also confirmed in a British meta-analysis by Shaw and colleagues, ${ }^{11}$ who found that specifically selected patients could be safely treated in a same-day to short-stay pathway and that the patients were amenable to this model. They also reported a low number of 30-day readmissions. This is consistent with the findings of and discussion in Hanley and colleagues, ${ }^{10}$ Dosluoglu and colleagues ${ }^{12}$ and Moscato and colleagues; ${ }^{13}$ all of these authors reinforced the importance of careful patient selection. Finally, the Canadian Institute for Health Information reported that $5.6 \%$ of all hospital admissions in Canada had at least 1 occurrence of harm in 2014-2015. The costs for these events were estimated to total $\$ 685$ million; ${ }^{14}$ thus, we deduce that by mitigating the risks of hospital- and procedure-related exposure to harm, we will provide additional safety benefits to our patients. 


\section{Limitations}

One of the limitations of our study was that in $50 \%$ of cases there was no clear documented reason for the extended LOS in the patient's hospital chart. Other limitations include those associated with retrospective studies (bias, sampling errors and imbalances in other factors). In the data there were also few of some types of complications available for analysis. Owing to the small numbers of cases (e.g., neural issues) the results should be interpreted with caution. An analysis with a larger data set is needed.

\section{Conclusion}

To the best of our knowledge, this is the first Canadian study of potential drivers of increased LOS, and therefore costs, following elective EVAR. By leveraging the data generated by SVS-VQI, multidisciplinary interventions allowed us to shorten our LOS in a short period of time and save dollars without risking patient safety. We believe that using SVS-VQI has assisted us to study our patient population with a significant benefit to all stakeholders. Patient expectations and social issues need to be managed effectively at the outset of treatment.

Acknowledgement: The authors thank Dr. Janice Montbriand for her assistance with the statistical analysis.

Affiliations: From the Division of Vascular Surgery, Peter Munk Cardiac Centre, University Health Network, Toronto, Ont. (Eisenberg, Roche-Nagle, Lindsay, Oreopoulos); the Faculty of Medicine, University of Toronto, Toronto, Ont. (Roche-Nagle, Lindsay, Oreopoulos); and the Division of Vascular Interventional Radiology, Peter Munk Cardiac Centre, University Health Network, Toronto, Ont. (Roche-Nagle, Oreopoulos).

Competing interests: None declared.

Contributors: All authors designed the study. N. Eisenberg acquired the data, which all authors analyzed. All authors wrote the article and critically reviewed it. All authors approved the final version to be published.

\section{References}

1. Canadian Institute for Health Information. Health spending in Canada reaches \$264 billion. Ottawa: Canadian Institute for Health Information. Available: https://www.cihi.ca/en/health-spending-in-Canada -reaches-264-billion (accessed 2020 Feb. 5).

2. Society for Vascular Surgery Vascular Quality Initiative. SVS-VQI [Internet]. Available: https://www.vqi.org/ (accessed 2017 Jan. 16).

3. American College of Surgeons. ACS National Surgical Quality Improvement Program [Internet]. Chicago: American College of Surgeons. Available: https://www.facs.org/quality-programs/acs-nsqip (accessed 2017 Nov. 23).

4. Agency for Healthcare Research and Quality. Plan-do-study-act (PDSA) cycle [Internet]. Rockville (MD): Agency for Healthcare Research and Quality; 2008. Available: https://innovations.ahrq.gov/ qualitytools/plan-do-study-act-pdsa-cycle (accessed 2019 Apr. 16).

5. Krajcer Z. The preclose technique for AAA repair. Endovasc Today 2011;May:46-54.

6. King EG, Rybin D, Doros G, et al. Identification of preoperative risk factors for protracted length of stay after elective EVAR. $7 \mathrm{Am}$ Coll Surg 2015;221:S179.

7. Patel VI, Mukhopadhyay S, Conrad MF, et al. Predictors of length of stay following endovascular AAA repair. 7 Vasc Surg 2013;58:855.

8. Mehaffey JH, LaPar JD, Tracci MC, et al. Targets to prevent prolonged length of stay after endovascular aortic repair. 7 Vasc Surg 2015;62:1413-20.

9. Al-Zuhir N, Wong J, Nammuni I, et al. Selection, thirty day outcome and costs for short stay endovascular aortic repair (SEVAR). Eur 7 Vasc Endovasc Surg 2012;43:662-5.

10. Hanley SC, Steinmetz O, Mathieu ES, et al. Safety and feasibility of endovascular aortic aneurysm repair as day surgery. 7 Vasc Surg 2018;67:1709-16.

11. Shaw SS, Preece R, Stenson KM, et al. Short stay EVAR is safe and cost effective. Eur $\mathcal{F}$ Vasc Endovasc Surg 2018;57:368-73.

12. Dosluoglu HH, Lall P, Blochle R, et al. Ambulatory percutaneous endovascular abdominal aortic aneurysm repair. 7 Vasc Surg 2014; 59:58-64.

13. Moscato VP, O'Brien-Irr MS, Dryjski ML, et al. Potential clinical feasibility and financial impact of same-day discharge in patients undergoing endovascular aortic repair for elective infrarenal aortic aneurysm. 7 Vasc Surg 2015;62(4):855-61.

14. Canadian Institute for Health Information. Measuring patient harm in Canadian hospitals. Ottawa: Canadian Institute for Health Information; 2016. Available: https://secure.cihi.ca/free_products/cihi_ cpsi_hospital_harm_en.pdf (accessed 2019 May 29). 